\title{
Retinal remodeling under conditions of organotypic 3D culturing in vitro and after damage in vivo in lower and higher vertebrates
}

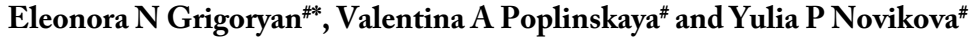 \\ Institute of Developmental Biology, Russian Academy of Sciences, Vavilov str. 26, 119334 Moscow, Russia \\ \#These authors contributed equally to the study
}

\begin{abstract}
Comparative analysis of retinal remodeling (RR) after damage in species capable and incapable to mobilize endogenous cell reserves provides an insight as to how limitations on retina restoration in humans can be overcome. RR is a phenomenon accompanying the loss of photoreceptor cells in various diseases and experimental models. Our study on the adult newt and rat retinas damaged in vivo or cultured in vitro is an attempt to reveal universal and specific features of RR in the aspects of cell behavior and tissue anatomy. When newt retina is damaged by light in vivo or placed in tissue culture, a regenerative response is observed from four cell populations: retinal pigment epithelium (RPE), retinal growth zone, displaced bipolar-like cells, and macroglia. Cells of the first three populations migrate, divide, and differentiate to replace lost photoreceptors, while the macroglia shows a gliotic response. In the rat retina, RPE cells in damaged sites change their phenotype, migrate, rarely divide, and often undergo apoptosis; in parallel, interneurons move to the site of photoreceptor damage, and Muller cells respond by hypertrophy. Cells at the periphery of the rat retina are not involved in RR, and there are no signs of cell division and reprogramming for the functional replacement of lost neurons. Thus, RR events in the rat and newt are comparable, except that cell behavior during RR in the newt follows the developmental pattern and, hence, this process can be regarded as true retinal regeneration rather than mere retinal reconstruction, as in the rat.
\end{abstract}

\section{Introduction}

Retinal remodeling in the eye of vertebrates, including humans, involves multiple molecular and cellular events taking place in response to disease (such as retinitis pigmentosa, Usher syndrome, age-related macular degeneration, etc.) or experimental damage. Whatever the cause, the neural retina responds to the loss of photoreceptor afferent activity by altering the functions and cooperative interactions of undamaged cells remaining in the tissue. This may involve a wide spectrum of processes such as neuronal reprogramming, neuritoand synaptogenesis, changes in cell signaling, migration and death of neurons, hypertrophy of Müller glia, and retinal pigment epithelium (RPE) cell invasion [1,2]. Some of these pathological changes take place immediately upon the initiation of photoreceptor cell stress, whereas others begin only after part of the photoreceptor cell population dies off. Studies on these processes and knowledge of retinal remodeling in general are important for developing approaches to treatment of retinal pathologies by means of gene therapy, neuronotropic factors, stem and progenitor cells, and tissue transplantation (implantation) methods.

Numerous studies on animal models have provided essential information for understanding tissue, cellular, and molecular events involved in post-damage retinal remodeling in humans. In particular, it has been shown that this process has a universal pattern independent of the cause of photoreceptor degeneration [3]. Therefore, we considered it expedient to compare basic features of structural retinal remodeling upon in vivo damage by bright light with those under conditions of organotypic culturing in vitro in two animal models: the newt (Urodela), which is highly capable of tissue regeneration, and the rat, whose retina does not regenerate. Such a comparison can provide an insight as to what is required for structural remodeling of the retina to result in true regeneration of this tissue, rather than in the mere maintenance of its integrity.

The neural retina in adult newts is capable of regeneration even after its surgical removal, as well as after cutting the optic nerve and blood vessels [4-6]. Moreover, it shows replenishment of the photoreceptor population upon detachment from RPE [7], and even a new (second) retina can be formed under such conditions [8]. With regard to the wide spectrum of its regenerative abilities, we used the newt retina to gain an insight into the pattern of structural rearrangements during its restoration based on internal cell sources. This approach can provide plenty of information requisite, in particular, to solving the problem of correct transplantation of stem or progenitor cells for treatment of retinal diseases in higher vertebrates (including humans), which have lost regenerative capacity.

Cell sources of retina regeneration in the newt have been studied in detail. The main source is the RPE. After the removal of the neural retina, it is reprogrammed so as to generate a transient blast cell

Correspondence to: PhD, Dr. (Sci. biol.) Eleonora Grigoryan Lab. "Problems of Regeneration”, Kol'tsov Institute of Developmental Biology, Russian Academy of Sciences Vavilov str., 26, 119334 Moscow, Russia, Tel: +7(499)1350052; Fax: +7(499)1358012, E-mail: leonore@mail.ru

Key words: newt, rat, retina, photoreceptor cell damage, regeneration, reconstruction, cell sources

Received: January 16, 2016; Accepted: February 12, 2016; Published: February 15,2016 
population, which gives rise to all variety of neuronal and glial cell types subsequently forming a fully functional retina [9-11]. Poorly differentiated cells of the eye growth zone (pars ciliaris and ora serrata) provide another, relatively small source for replenishing cell loss at the periphery of the retina [6]. The third source consists of "under differentiated" bipolar-like precursor cells with Landolt's club, which can move toward the sclera and differentiate further, replacing the lost photoreceptors [12].

In mammals, rats in particular, damage to the photoreceptor layer does not lead to in situ activation of any potential progenitor cells, and natural substitution of cell types in the retina is therefore impossible, unlike in lower vertebrates (e.g., fishes). However, there is evidence for the reactivity of macroglia (Müller cells), which form a glial scar filling the space left by degenerated photoreceptors. This is a universal neural tissue response to injury that is observed in low and higher vertebrates [13]. It is these cells and also a small population of pigment cells in the ciliary body, which display some stem cell properties in vitro [1416], that are relied upon as probable endogenous sources to restore the retina [17].

Although the retina of higher vertebrates and humans does not regenerate, it shows high cellular and molecular plasticity. Thus, the consequences of its detachment from the RPE are not limited to the disruption of photoreceptor outer segments but may also include changes in photoreceptor synapses and structural rearrangements in the layers of second- and third-order neurons, which result in functional disturbances even after successful retinal reattachment [18].

Therefore, it appears relevant to evaluate primary and secondary structural changes in the retina that have been observed in the in the models of organotypic 3D culture in vitro and light-induced retinal degeneration (LIRD) in vivo. This paper summarizes the results of our experiments in these models with the retina of lower (the newt) and higher vertebrates (the rat).

\section{Material and methods}

\section{Animals and ethical procedures}

Wistar albino rats and Pleurodeles walt newts were from the vivarium (aquarium) of the Kol'tsov Institute of Developmental Biology, Russian Academy of Sciences. All experiments were performed in accordance with regulations for animal keeping and experimentation approved by the Commission on Bioethics of the Russian Academy of Sciences and the Ethics and Animal Care Committee of the IDB RAS.

\section{LIRD in newts}

Bright light treatment was performed as described in detail in our previous publication [19]. Briefly, adult newts were kept in the dark for $24 \mathrm{~h}$ and then placed in a container, one-third full of water, with light-proof walls (covered with aluminum foil) and a $60 \mathrm{~W}$ argon lamp installed $30 \mathrm{~cm}$ above the bottom, where they were exposed to continuous illumination for 40 days at a light intensity of $1300 \mathrm{~lx}$ during the night and $1500 \mathrm{~lx}$ during the daylight period, as measured with a digital lux meter. Such a long exposure was used taking into account the low metabolic rate of these cold-blooded animals and, hence, slow progression of tissue degeneration and regenerative response. Control newts were kept under normal laboratory conditions at a natural photoperiod.

\section{LIRD in rats}

Experiment was performed with 2-month-old rats reared at a 12-h photoperiod. Animals of the experimental group were adapted in the dark for $14 \mathrm{~h}$ and then exposed to bright light for another $14 \mathrm{~h}$. The light source was an NC-DE 70W/DW RX7s metallic halogen lamp (Narva, Germany; luminous flux 5000-5500 lm) placed at $2 \mathrm{~m}$ from the cages with rats, so that the light intensity at the retina was about 2500-3000 lx. The control group consisted of rats of the same age kept under the same conditions but not subjected to such treatment.

\section{Culture of isolated newt retina}

Newts were anesthetized with tricaine (MS-222, $1: 1500$ ), and the eyes were removed and microsurgically dissected in the culture medium to isolate the retina from the RPE (relatively shallow interdigitation between the photoreceptor outer segments and the apical processes of RPE cells allowed clean isolation of this tissue). Retinal explants were transferred to $20-\mathrm{mL}$ plastic flasks (Wheaton, United States) with $5 \mathrm{~mL}$ of medium 199 diluted by half with deionized water and supplemented with $1 \mathrm{M}$ HEPES ( $\mathrm{pH}=7.4), 80 \mathrm{mg} / \mathrm{mL}$ gentamicin, and $10 \%$ fetal bovine serum (HyClone, United States). The flasks were placed in a Rotamix RM1 rolling shaker (Elmi, Latvia) set at $60 \mathrm{rpm}$, and the explants were cultured at $22-23^{\circ} \mathrm{C}$ for 14 and 28 days, replacing the medium once a week. The culture period was longer than in experiments with rats (see below) because of the relatively low rate of cellular processes in amphibian tissues at physiological temperatures of culturing.

\section{Culture of isolated rat retina}

The eyes of 2- to 3-month old rats were removed, rinsed with 70\% ethyl alcohol, and placed in cold DMEM. Under sterile conditions, the posterior eye segments were cut out, placed in the medium with $5 \mathrm{mM}$ EDTA for $3 \mathrm{~min}$, and further dissected to isolate the retina. The explants were transferred to 20-mL Wheaton flasks with $5 \mathrm{~mL}$ of culture medium ((Dulbecco's Modified Eagle Medium (DMEM) with $0.6 \mathrm{mg} / \mathrm{mL}$ glutamine, $10 \%$ fetal bovine serum (FBS), and $1 \%$ penicillin-streptomycin)) and cultured in a roller shaker (60 rpm) at $35.5^{\circ} \mathrm{C}$, in the dark, for 10 days without replacing the medium.

\section{Histological analysis}

The results obtained in LIRD experiment on the newt were evaluated by microscopic analysis of conventional $(5-7 \mu \mathrm{m})$ and semithin sections $(1 \mu \mathrm{m})$. In the former case, a routine histological procedure was used to prepare complete series of sections, which were stained with Caracci hematoxylin and examined under an Olympus AH-3 (Olympus Optical, Japan) or Jenaval (Carl Zeiss, Germany) microscope. To prepare semi-thin sections, the animal was anesthetized with $2 \%$ urethane, and the eyes were removed and fixed with paraformaldehyde-glutaraldehyde. The posterior eye segment (with neural retina, RPE, choroid, and sclera) was isolated and cut into four radial sectors, which were kept in the same fixative for 24 $\mathrm{h}$ and then postfixed with $\mathrm{OSO}_{4}$, dehydrated in an ascending alcohol series and propylene oxide, and embedded in Araldite. Serial semithin sections were cut along the long axis of photoreceptor outer segments, placed onto glass slides, stained with toluidine blue, and examined under an Olympus CX41 microscope at 1000× magnification. Images of the preparations were taken with a digital camera attachment and processes using the Lite software.

Samples for analysis of LIRD in the rat were collected immediately after light exposure and 14 days later. The rats were anesthetized by intraperitoneal injection of chloral hydrate (Sigma, United States; $500 \mathrm{mg} / \mathrm{kg}$ body weight), decapitated, and the eyes were removed and fixed in Bouin's fluid for $48 \mathrm{~h}$. Thereafter, the eyes were cut along the 
limbus to isolate their posterior segments, which were histologically processed by standard methods, cut into serial sections, and stained with hematoxylin and eosin. Microscopic analysis was performed as described above. Histological treatment of retinal samples cultivated in vitro was similar with that described above for LIRD experiments.

\section{Results}

\section{LIRD in newts}

The retina of newts exposed to bright light had the same cellular composition as in untreated animals kept under normal conditions [7]. It consisted of the outer nuclear layer (ONL) with three types of photoreceptor cells (rods, single cones, and double cones), the inner nuclear layer (INL) with different classes of bipolar and amacrine cells, and the ganglion cell layer. However, the morphology of ONL differed from the norm, primarily in the center of the eye back wall: the photoreceptor outer segments were reduced in length, their arrangement pattern was disturbed, and other signs of degeneration were observed. The newt retina proved to be generally resistant to light damage, but dead photoreceptor cell bodies (mostly rods) could be detected in the ONL, although their proportion was small (about 0.4$0.5 \%$ of its total cell population). Single dead cells were also found in the INL, while the ganglion cell layer remained morphologically normal. Distinct changes were observed in the RPE underlying the sites of photoreceptor damage. Having lost contact with photoreceptors, RPE cells did not degenerate but often detached from Bruch's membrane and moved out of the layer toward the vitreous body, undergoing transdifferentiation. Some of these cells functioned as phagocytes (Figure 1a), while others, still retaining melanin granules (their natural marker), penetrated the retina (Figure 1b), sometimes as deep as the INL, and gradually lost their initial phenotype, forming clusters of blast cells capable of substituting neurons in both ONL and INL (Figure 1c).

After 40-day exposure to bright light, certain secondary structural rearrangements also occurred in the outer plexiform layer lying between the ONL and INL. In particular, a significant increase was observed in the number of bipolar-like cell precursors, which were previously described as a specific population of bipolars with Landolt's club that are displaced there from the INL [12] (Figure 1d). These cells gradually fitted into the ONL and, together with descendants of

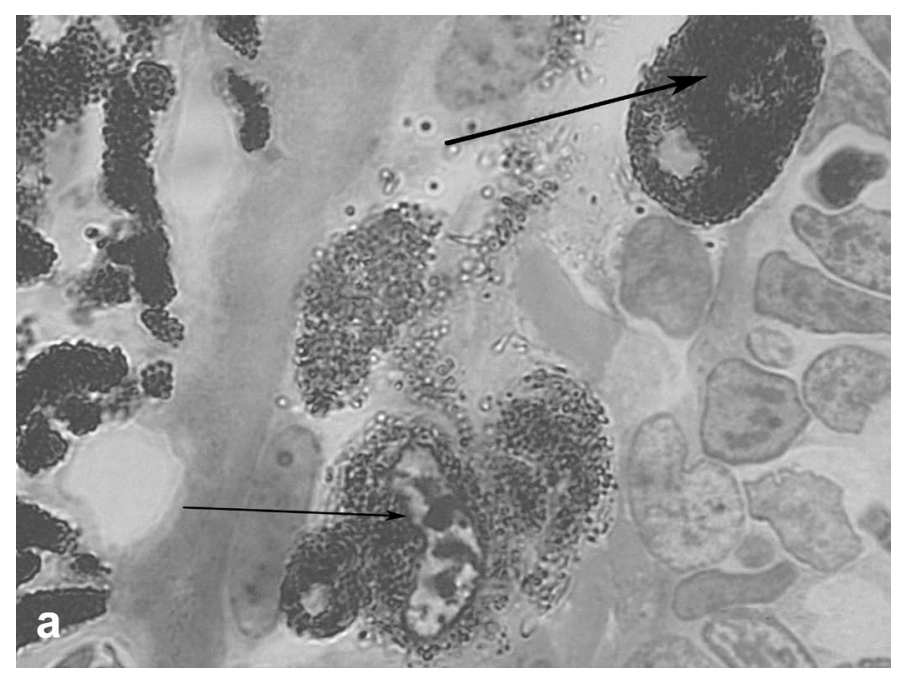

Figure 1a. Retinal cell behavior in newts exposed to bright light illumination - withdrawal from the layer and conversion of RPE cells into macrophage (thick arrow) and neural precursor cell (thin arrow).

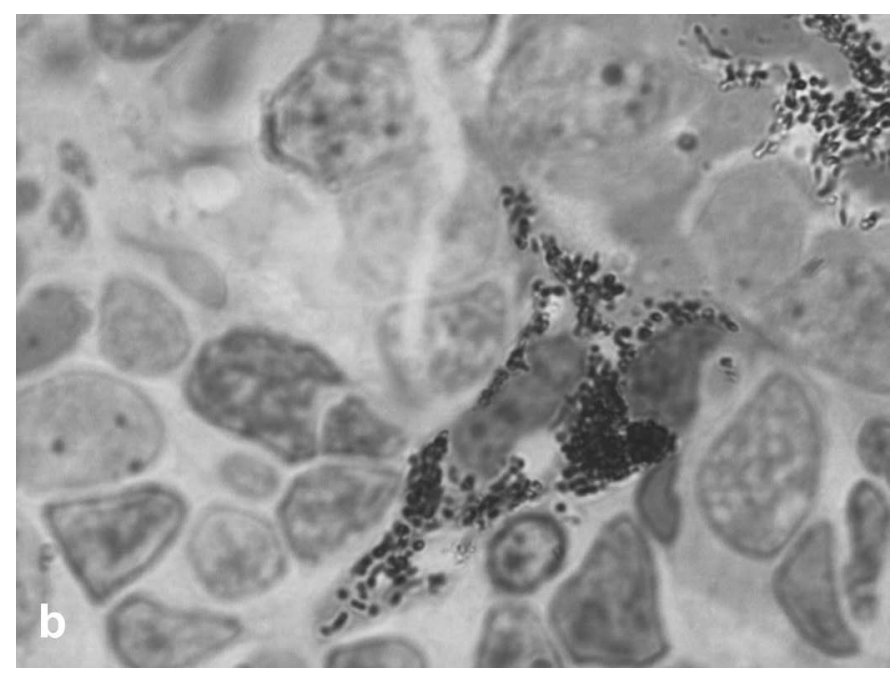

Figure 1b. Retinal cell behavior in newts exposed to bright light illumination-still heavy pigmented RPE - derived cell precursor penetrating the retina.

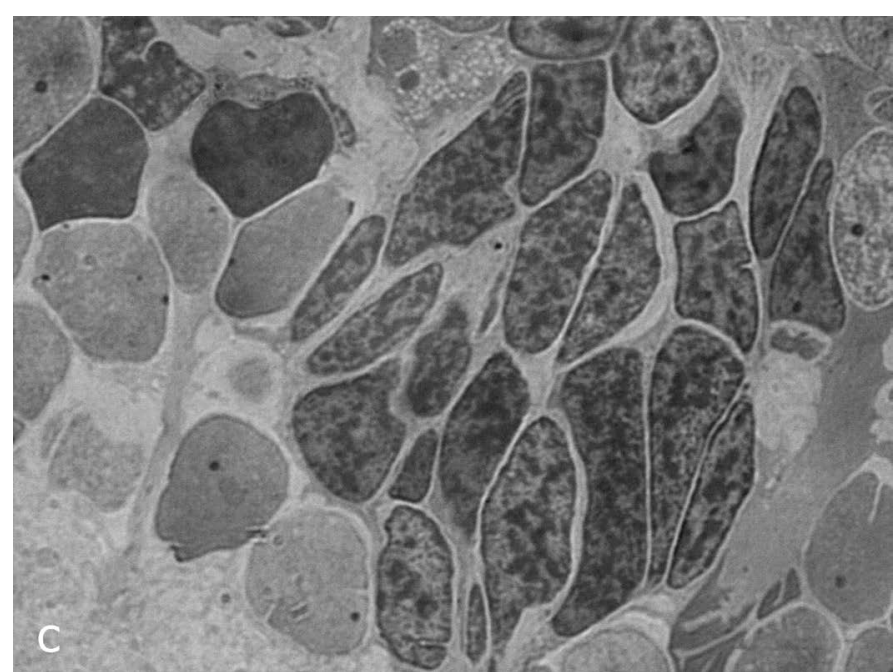

Figure 1c. Retinal cell behavior in newts exposed to bright light illumination - group of dedifferentiated RPE - derived cells with condensed chromatin located among differentiated neurons of the inner nuclear layer.

RPE cells, replenished the loss of photoreceptors by differentiation of photoreceptor outer segments from the Landolt's clubs. In parallel, new precursors migrated to the inner plexiform layer from the INL, with consequent decrease in the cellularity of the latter. They were oriented perpendicular to the layer of horizontal cells and morphologically differed from other cell types found in the inner plexiform layer. In the growth zone of the retina, which is also known to contain a pool of poorly differentiated precursors [6], some cells were in $M$ phase, indicating that this pool was activated to proliferation (Figure 1e).

In semithin sections of light-irradiated newt retina, macroglial Müller cells were readily detectable due to their enlarged, unevenly shaped cell bodies and thick accessory prolongations indicative of their hypertrophy (Figure 1f). These prolongations were sometimes so thick that some photoreceptor and amacrine cell bodies were entirely "embedded" in their cytoplasm. Subsequent (secondary) changes included the formation of bucklings, folds and rosettes surrounded by both initial neurons of different types and new, as yet poorly differentiated cells (Figure 1g). 


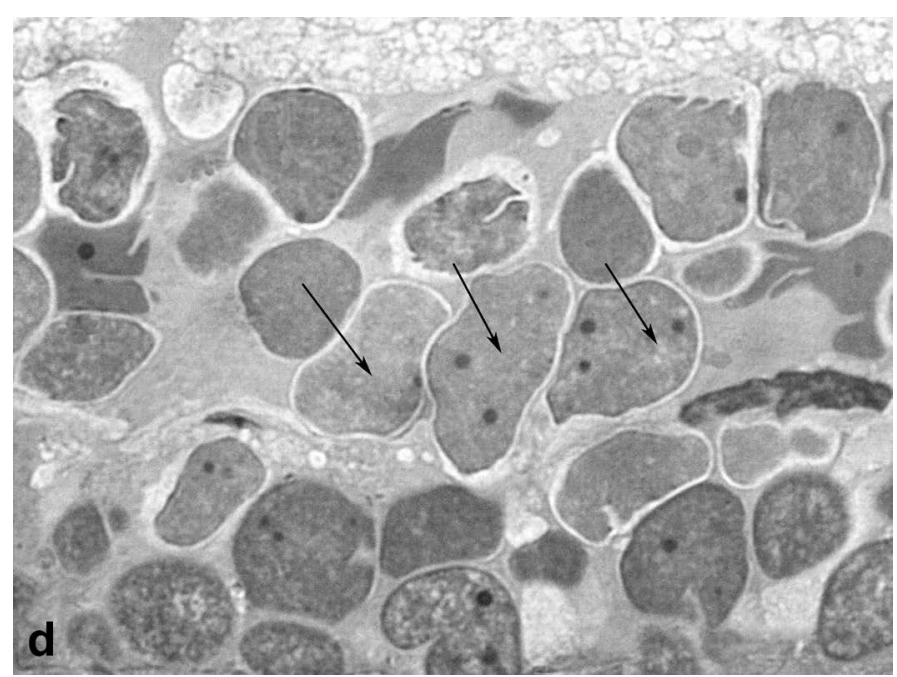

Figure 1d. Retinal cell behavior in newts exposed to bright light illumination - bipolar cells (arrows) displaced to the outer nuclear layer from the inner one and located just above horizontal cell layer

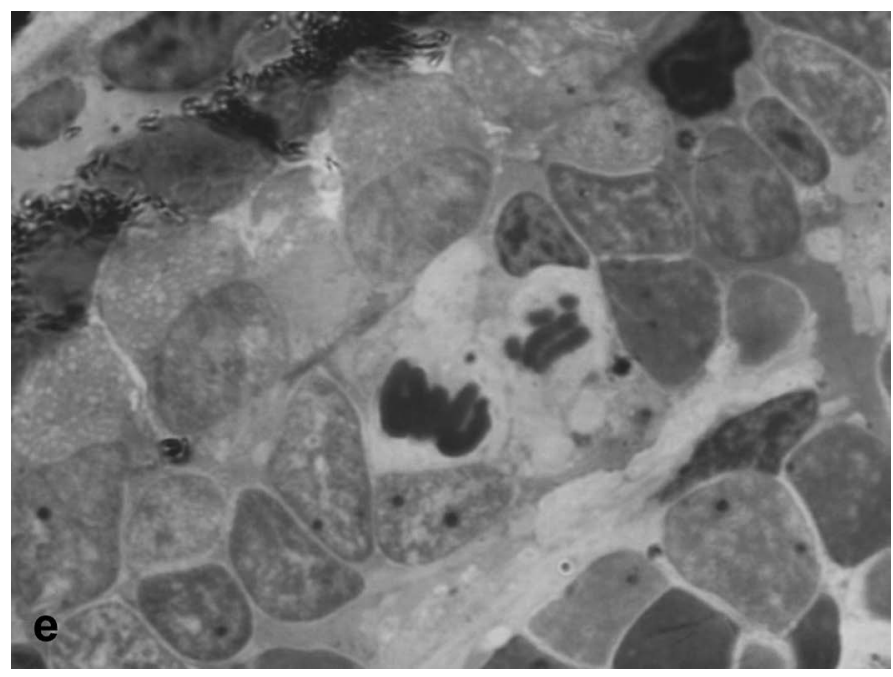

Figure 1e. Retinal cell behavior in newts exposed to bright light illumination - mitosis in the outer nuclear layer at the periphery of the retina, close to the retinal growth zone.

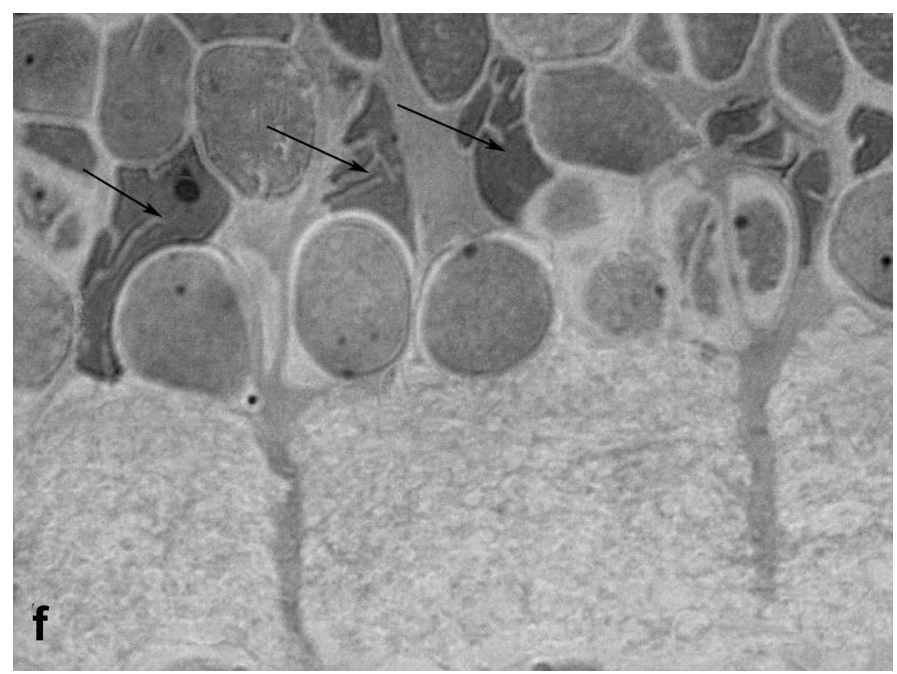

Figure 1f. Retinal cell behavior in newts exposed to bright light illumination - Muller glial cells (arrows, big nuclei of non regular form) locate among interneurons of inner nuclear layer and show hypertrophy.

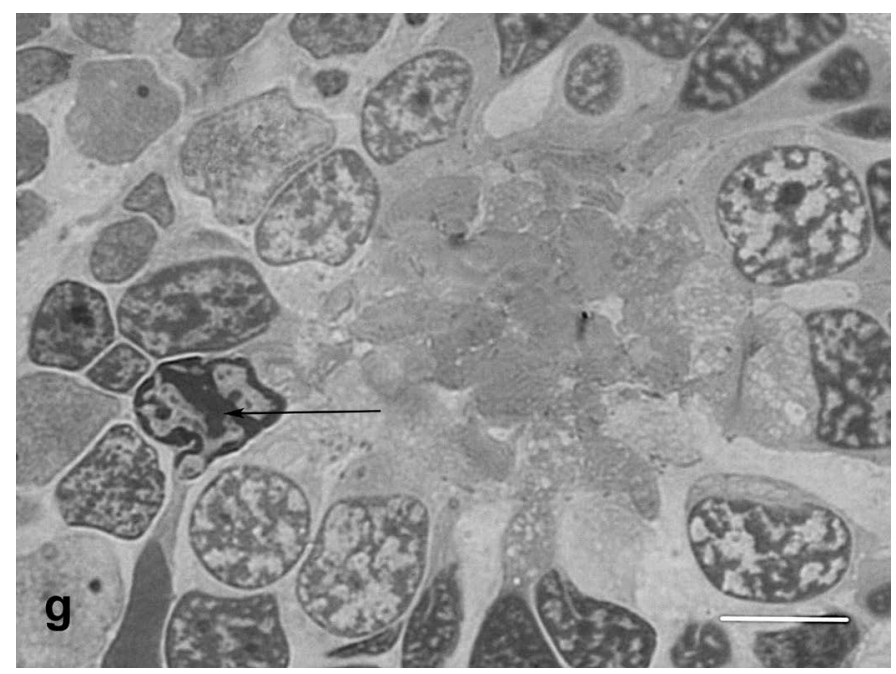

Figure 1g. Retinal cell behavior in newts exposed to bright light illumination - the rosette surrounded by both, original photoreceptors and new, yet poorly differentiated cells with condensed chromatin (arrow). Semi-thin sections, toluidine blue, the scale bars represent $10 \mu \mathrm{m}$.

Thus, a comparative analysis of retinal morphology in lightirradiated and control newts showed that retinal remodeling in these animals involves the following events: reduction, derangement, and degeneration of the photoreceptor outer segments, with only a minor proportion of photoreceptor cell bodies dying off; activation, displacement, and subsequent differentiation of bipolar-like precursor cells; response from RPE cells, which detach from the epithelial layer, migrate, and acquire the properties of precursor cells and differentiated phagocytes; and, in addition, hypertrophy of Müller cells. It should be emphasized that the main feature of retinal remodeling in the newt is that at least three cell populations (growth zone cells, RPE, and displaced bipolar-like cells with Landolt's club) contribute to the replacement of neurons lost as a result of LIRD.

\section{LIRD in rats}

The state of the rat retina immediately after bright light exposure was evaluated by several morphological criteria, which provided evidence for degenerative processes in this tissue. They were manifested in the disarrangement of photoreceptor outer segments, initiation of apoptosis and loss in photoreceptor cell bodies (Figures 2a,2b), and their displacement toward the sclera or the vitreous, as well as in the altered behavior of RPE cells at sites of photoreceptor damage, which lost contact with photoreceptors and Bruch's membrane, detached from the epithelial layer, and transformed into phagocytes ingesting dead photoreceptors (Figures $2 \mathrm{c}, 2 \mathrm{~d}$ ). These events are generally similar to those described in previous LIRD models with different illumination regimes [20,21]. An analysis of regional differences in light damage to the retina showed that its superior temporal zone is the most sensitive, which also agrees with topographic data obtained in other LIRD models [22].

On day 15 after light exposure, not only local thinning or even disappearance of ONL was observed; the inner portion of the retina also proved to be affected, which was manifested in disturbances in the cytoarchitecture of INL and displacement of interneurons toward the sclera. Moreover, sites of damage were detected in the RPE, and Müller cells in the zone of ONL damage or near it showed an increase in the number and thickness of accessory prolongations (Figure 2e). Subsequent 


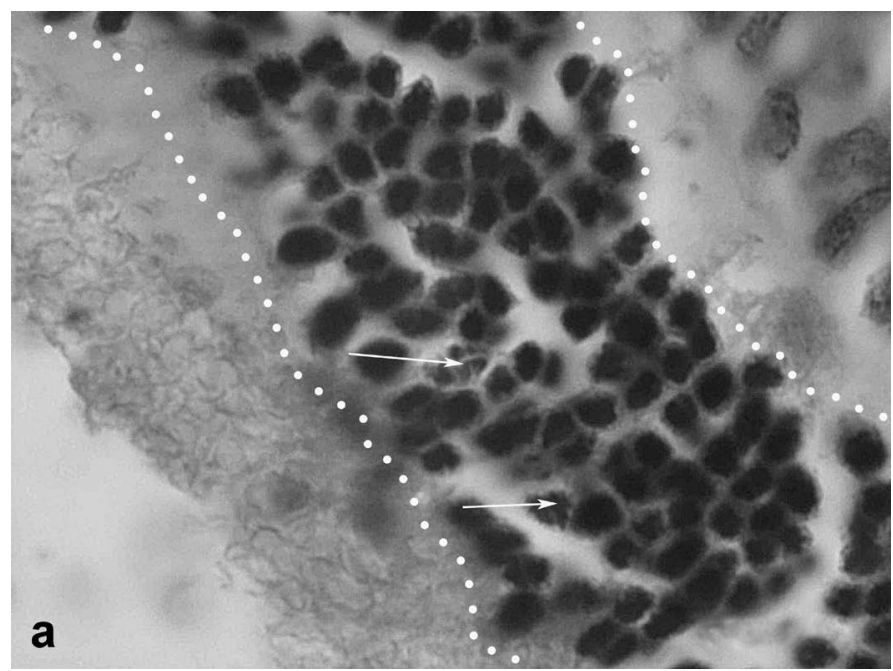

Figure 2a. Retinal cell behavior in rats exposed to bright light illumination - early cellular events in outer nuclear layer (outlined) induced by LIRD: disarrangement of photoreceptor outer segments (out of the line, on the left) and initiation of apoptosis in the layer (arrows).

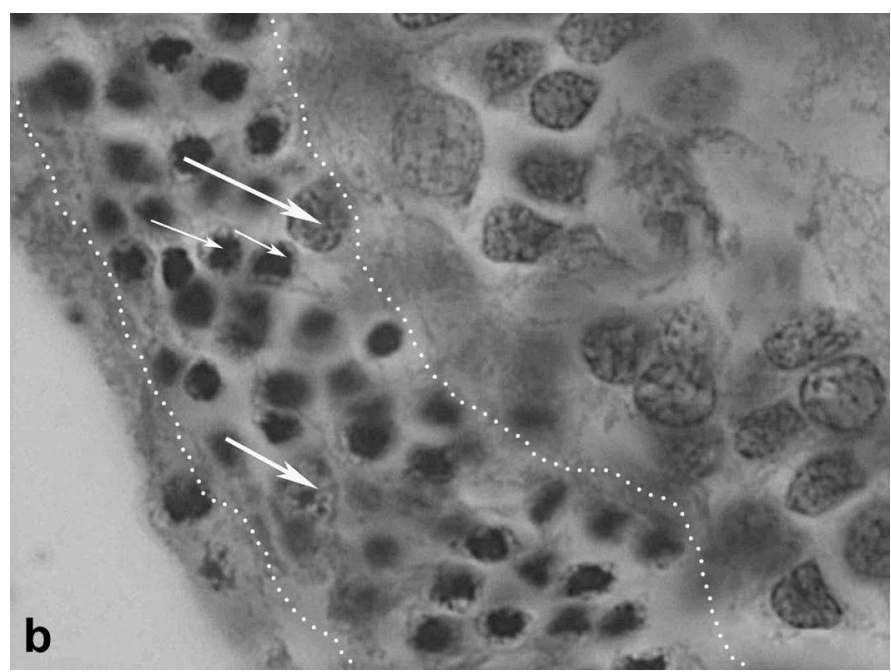

Figure 2b. Retinal cell behavior in rats exposed to bright light illumination - late cellular events in outer nuclear layer (outlined) induced by LIRD: disappearing of photoreceptor segments' layer, apoptosis and loss of photoreceptor cell bodies and displacement outward of cells from inner nuclear layer (thick arrow).

changes in the light-irradiated retina included the formation of bucklings, folds, outflow channels, and rosettes (Figure 2f). As in the newt, the ganglion cell layer in the rat retina has largely retained its initial morphology in the course of LIRD.

Thus, exposure to bright light in adult rats initiates degeneration of the photoreceptor cell layer, which is followed by remodeling of the internal structure of the retina, including not only RPE and ONL but also its inner part (interneurons and macroglia). The basic events during retinal remodeling in rats are as follows: death of photoreceptor outer segments and then of photoreceptor themselves; migration of RPE cells out of the epithelial layer accompanied by changes in their morphology and transformation into phagocytes that ingest dead photoreceptors; local displacement of interneurons toward the choroid at sites close to ONL damage; and reactive gliosis, i.e., an increase in the number and thickness of accessory prolongations of Müller cells. Unlike in newts, where dying photoreceptors are replaced by precursor cells from different populations, no involvement of potential precursors from the retina growth zone or RPE is observed, and the outward displacement of interneurons in the rat retina does not provide for functional substitution of degenerating cells but simply serves to fill the gaps resulting from cell loss in the INL.

\section{Morphological changes in cultured newt retina}

The structural organization of the normal retina in adult $\mathrm{Pl}$. walt newts is similar to that in other vertebrates and has been described in detail at light- and electron-microscopic levels [7]. In roller culture, retinal explants gradually curled up into closed spheroids (Figure 3a). After 14 days, some photoreceptors and cells in the inner portion of the retina died off, but the tissue retained its stratified structure (which later became disturbed). The ONL and INL near the zone of spheroid closure (corresponding to the retinal periphery) contained numerous cells in $\mathrm{M}$ phase. These cells in the ONL were located amid photoreceptor cell bodies, usually close to the outer limiting membrane (Figure $3 \mathrm{~b}$ ); in the INL, they often were found near accessory prolongations of Müller cells. Mitotic pictures were observed approximately in every second section, and there were up to five mitotic cells per section. A detailed

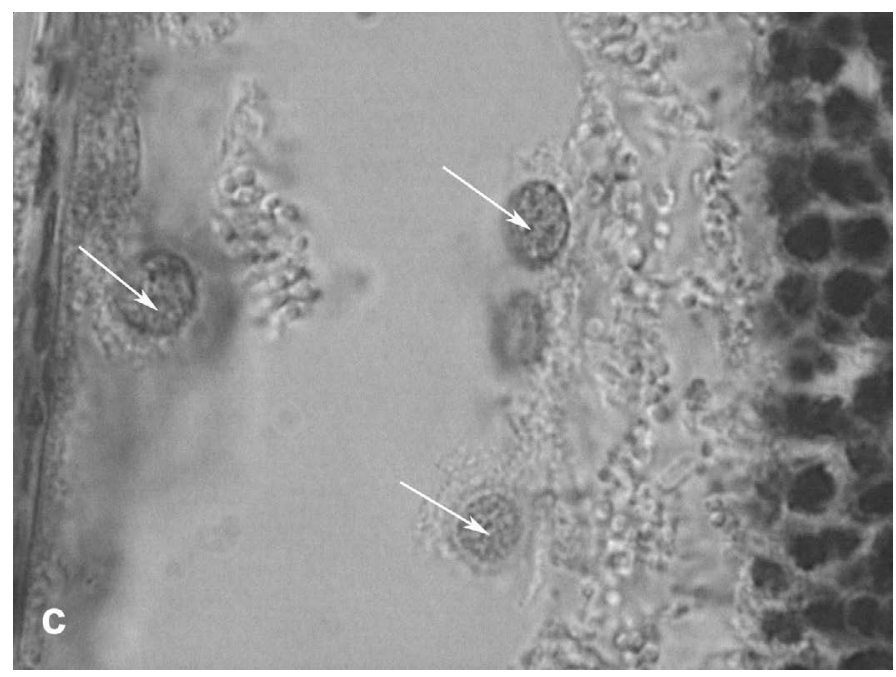

Figure 2c. Retinal cell behavior in rats exposed to bright light illumination - retinal pigment epithelial cells which detached from Bruch's membrane and became of macrophage-like ones.

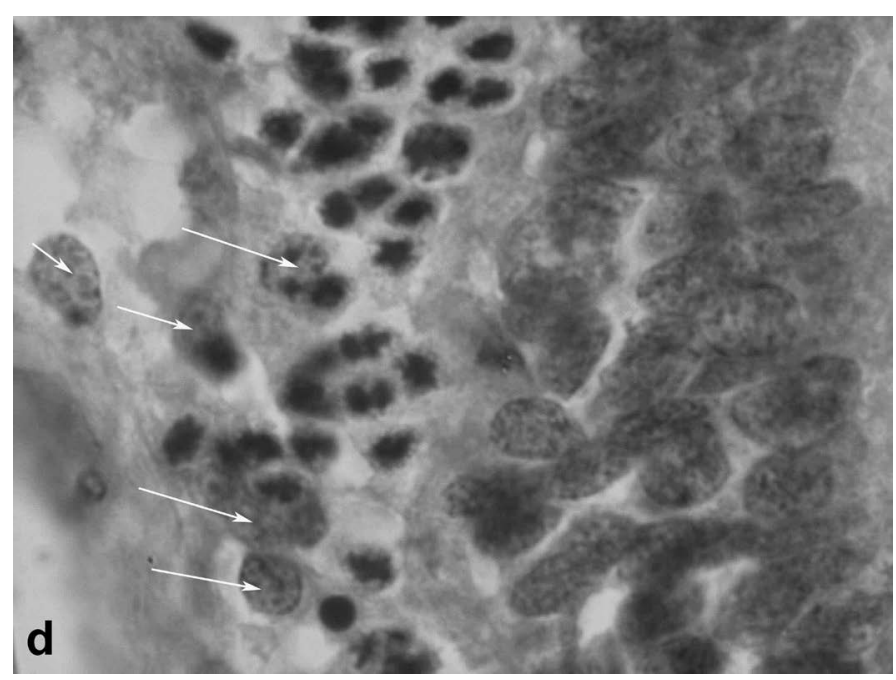

Figure 2d. Retinal cell behavior in rats exposed to bright light illumination - retinal pigment epithelial cells phagocytizing of dying photoreceptor cell bodies (arrows). 


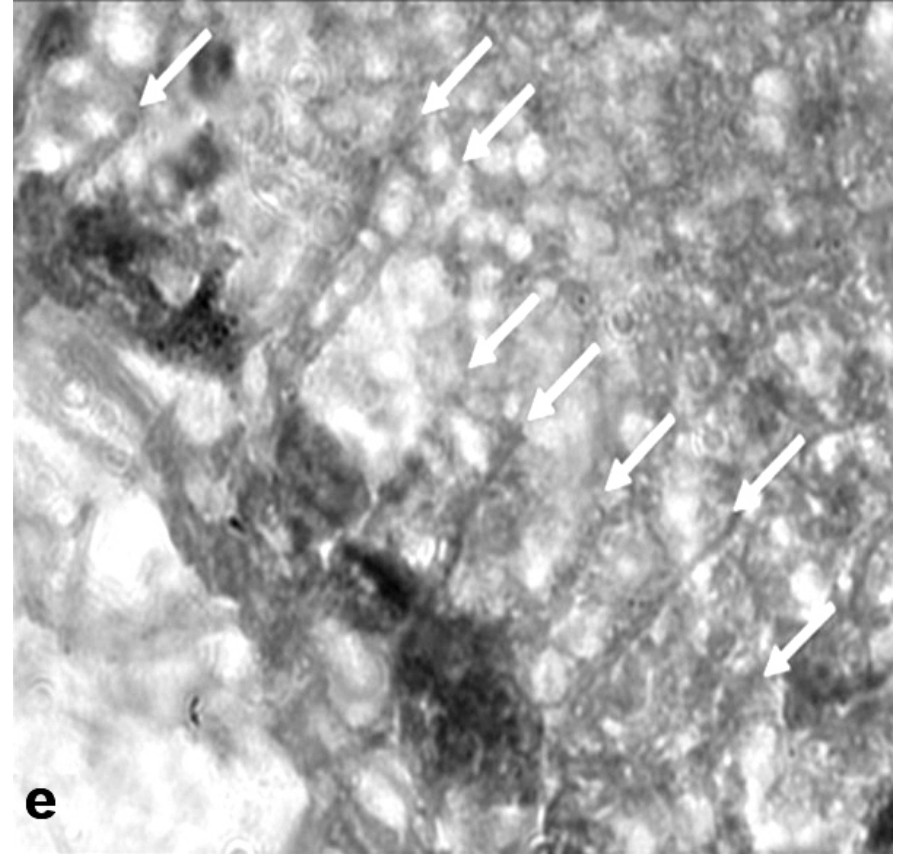

Figure 2e. Retinal cell behavior in rats exposed to bright light illumination - Mullerean glia cell hypertrophy manifested morphologically in changes of accessory prolongations: thick and frequent prolongations go through the inner plexiform layer, ganglion cell layer to the inner limiting membrane (arrows), (A-E) - the scale bar represents $10 \mu \mathrm{m}$.

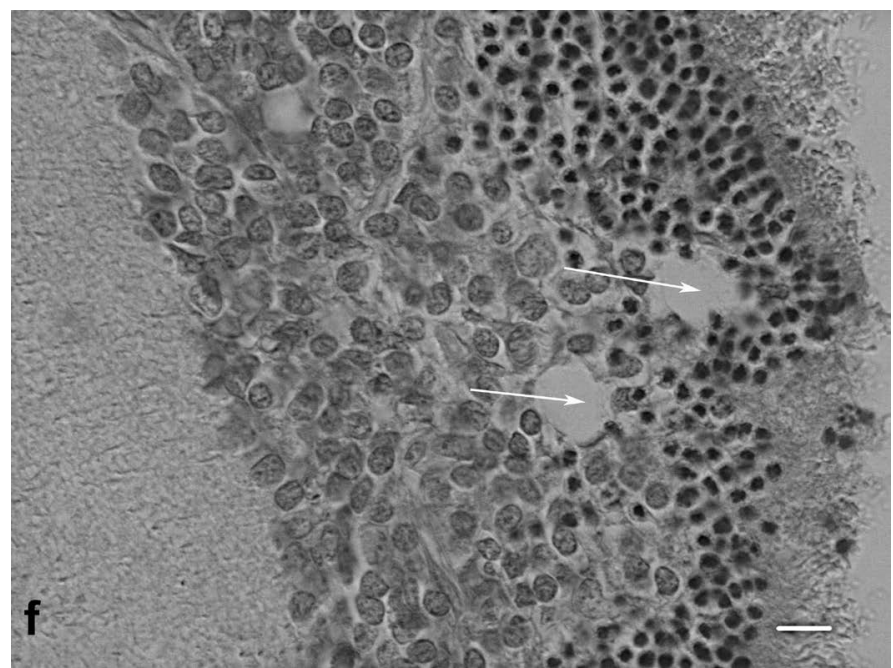

Figure 2f. Retinal cell behavior in rats exposed to bright light illumination - rosette and outflow channels in the outer and inner portions of the retina. The scale bar represents 5 $\mu \mathrm{m}$. Hematoxyline-Eosine.

description of the mitotic activity of precursor cells in the newt retina during organotypic culture is given elsewhere [23].

Cells radially migrating from the INL to the ONL were detected in some areas of the outer plexiform layer. Analysis of semithin sections revealed hypertrophy of Müller glial cells, which was manifested in significant enlargement of their nuclei, thickening of accessory prolongations, and increased number and size of the nucleoli (Figure $3 \mathrm{c})$. Some cells of this population were also in M phase. After 14 days in culture, the spheroid cavity contained only a few cells but was filled with neurites of ganglion cells, whose bodies remained in their own layer. Flows of cells migrating from the INL to the ONL and numerous mitoses could be seen in the area near the optic nerve exit. All these observations provide evidence that poorly differentiated precursor cells, which constitute the internal cell reserve for retina regeneration in the newt, are actively involved in the process of retinal remodeling in vitro. In our case, this applies to cells of the retina growth zone and bipolar-like cells from the INL but not to RPE cells, because the retina was isolated without the RPE.

Retinal explants cultured for 4 weeks were characterized by more extensive intermixing of layers and extension of neural processes to the spheroid cavity in the zones of spheroid closure and optic nerve exit (Figure 3d). Mitotic cells were more frequent than on day 14 and could be found in each section. A major proportion of cells in such spheroids had characteristic features of neuroblasts, such as nuclei with condensed chromatin and a very narrow cytoplasmic rim. This is evidence that the processes of cell migration, differentiation, and neurite outgrowth develop in the newt retina cultured in vitro and, along with proliferation of precursor cells, contribute to the general process of retinal remodeling in this species.

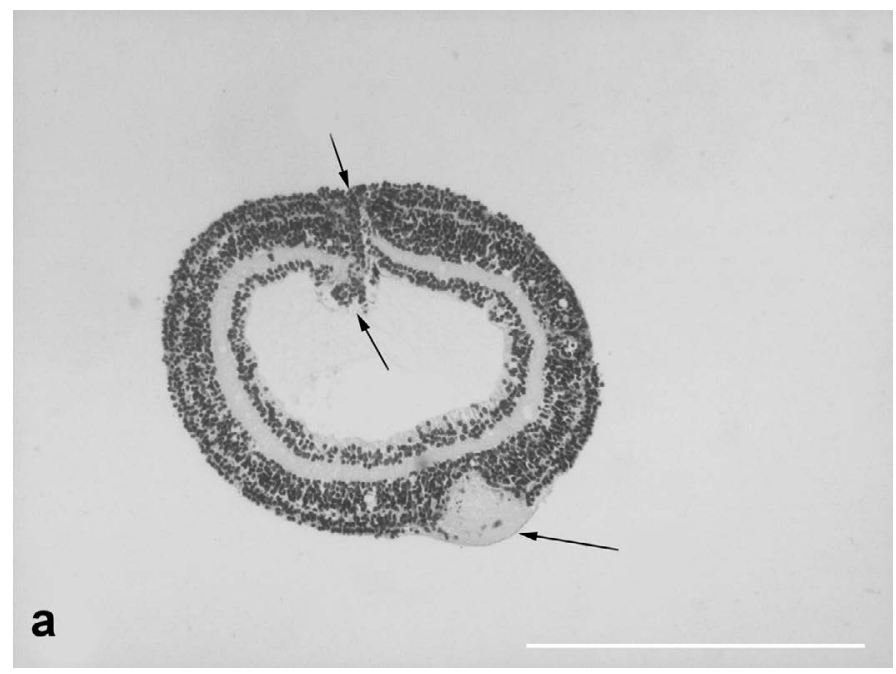

Figure 3a. Cell behavior in newt retina under conditions of long term organotypic roller culturing - general view of newt retina on the 14th day of 3D culturing in vitro; upper arrows show retinal periphery, lower ones - optic nerve stump, scale bar represents $500 \mu \mathrm{m}$.

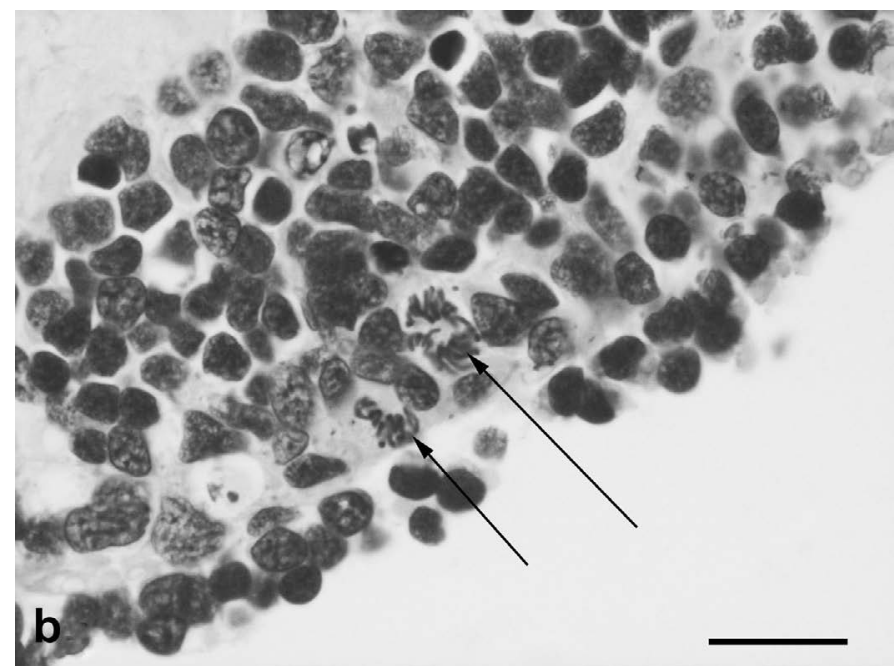

Figure 3b. Cell behavior in newt retina under conditions of long term organotypic roller culturing - mitoses in the outer portion of cultured newt retina (arrows), scale bar represents $20 \mu \mathrm{m}$. 


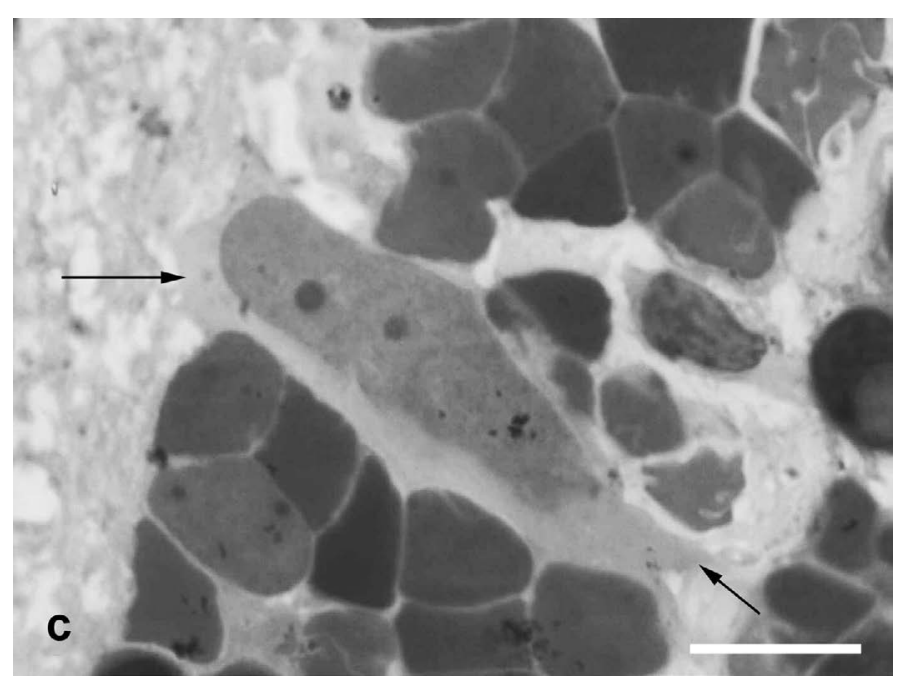

Figure 3c. Cell behavior in newt retina under conditions of long term organotypic roller culturing - Müllerean glia cell (arrows, big nuclei of non regular form) locates among interneurons of inner nuclear layer and shows hypertrophy, scale bar represents $10 \mu \mathrm{m}$.

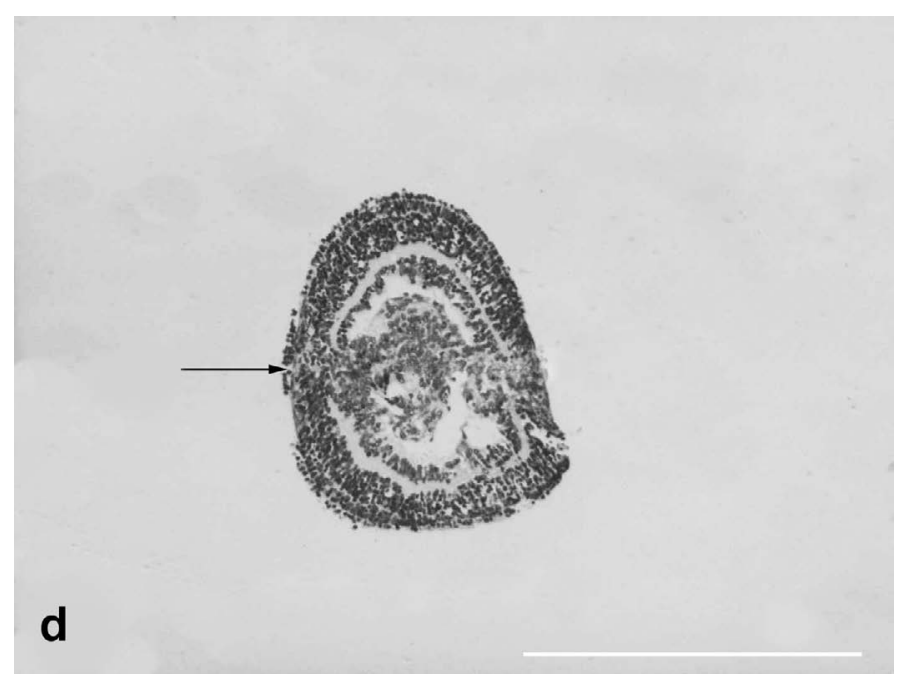

Figure 3d. Cell behavior in newt retina under conditions of long term organotypic roller culturing - general view of newt retina cultured for 4 weeks in vitro, arrow shows spheroid primary closure, scale bar represents $500 \mu \mathrm{m}$.

Analysis of semithin sections revealed a number of morphologically dedifferentiated cells that not only filled the spheroid cavity but were also localized in the ONL and INL, singly or in clusters (Figure 3e). It may well be that they substituted part of dead neurons, which were easy to identify in these layers. Cells in the zone of spheroid closure continued growing, actively migrated to the cavity, and aggregated there. As could be seen in sections through the center of the spheroid, these were dedifferentiated neuroblast-like cells of oval, elongateoval, or sometimes irregular shape that stained more lightly than the surrounding cell bodies of neurons, and their nuclei contained dense chromatin aggregates and one or two large nucleoli. They could be conventionally divided into two size categories, large and small cells. The former were apparently derived from cells of the growth zone, and the latter, from bipolar-like precursor cells of the INL. In the outer portion of the cultured retina the rosettes and outflow channels were often also observed (Figure 3f).

Thus, organotypic culturing of the newt retina is inevitably accompanied by cell death (mainly of photoreceptors at the surface facing the medium), and its remodeling under such conditions is obviously accounted for by the precursor cells and the processes of cell migration, active proliferation, and differentiation.

\section{Morphological changes in cultured rat retina}

The peripheral zone of the rat retina, topologically analogous to the wide ora serrata of the newt retina, consists of a narrow band of cells that have no processes and are incapable of proliferation (unlike in newts). Photoreceptors and cells in the inner retinal layers are much smaller than in newts and can be identified not so much by morphological criteria as by location. After 10 days in roller culture, retinal explants remained viable but underwent structural changes. First of all, this concerns their shape: the explants curled up into spheroids that were closed to different degrees, which largely determined not only the pattern of changes within retinal layers but also cell viability. In open spheroids, cell mortality was high, although

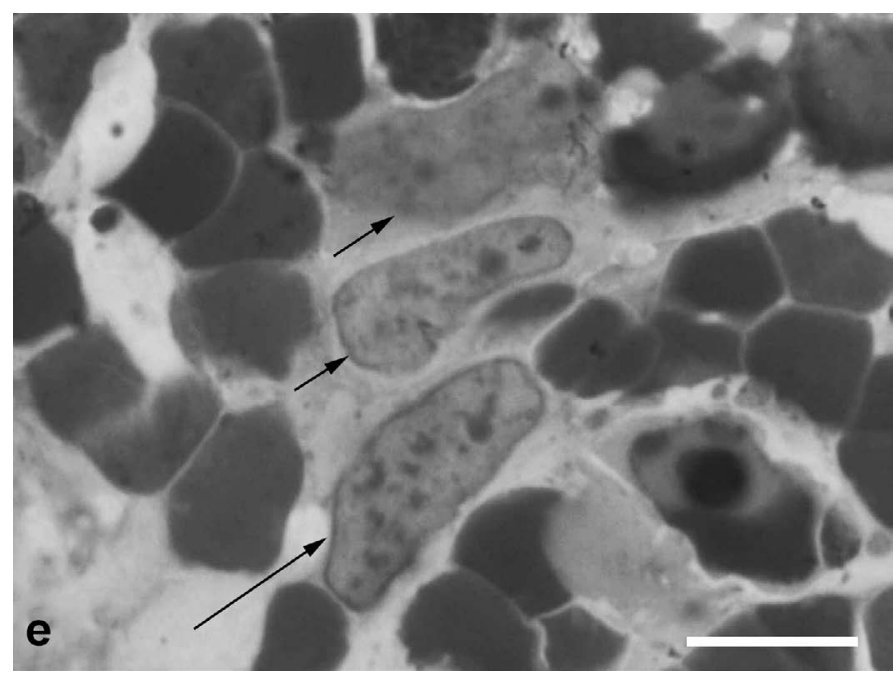

Figure 3e. Cell behavior in newt retina under conditions of long term organotypic roller culturing - dedifferentiated cells having characteristic features of neuroblasts (big nuclei and nucleoli, condensed chromatin) in the thickness of cultured newt retina, scale bar represents $10 \mu \mathrm{m}$

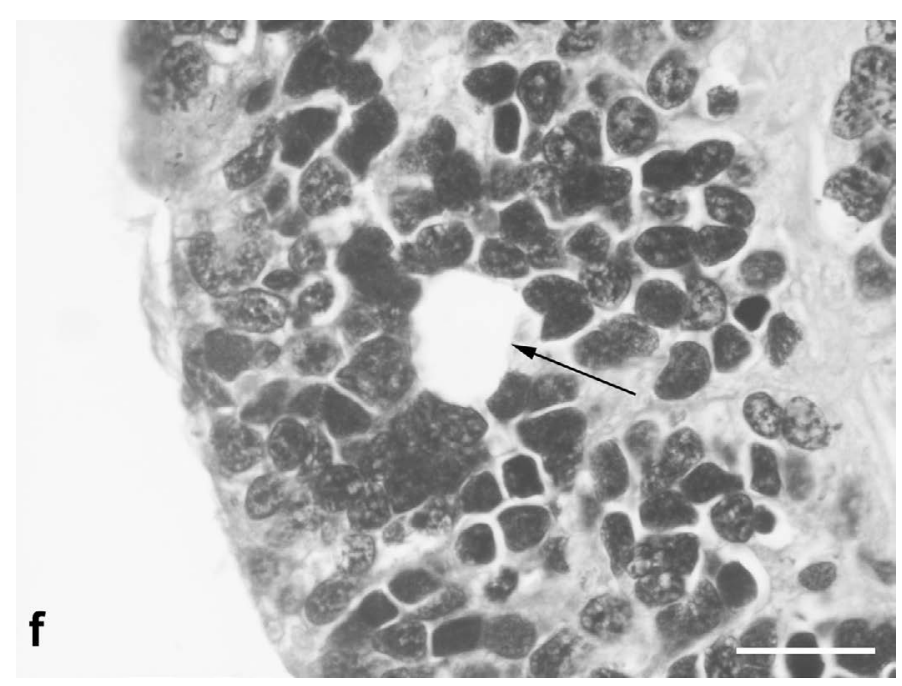

Figure 3f. Cell behavior in newt retina under conditions of long term organotypic roller culturing - a rosette formed in the outer portion of long term cultured newt retina, scale bar represents $20 \mu \mathrm{m}$; Hematoxyline-Eosine. 


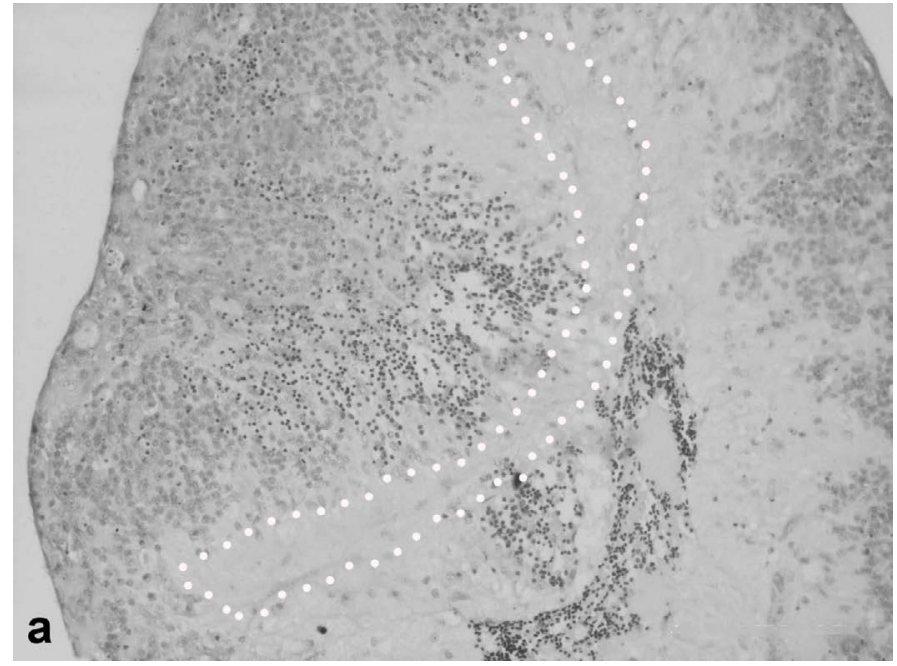

Figure 4a. Cell behavior in rat retina under conditions of long term organotypic roller culturing - view of the rat retina that has formed spheroid on the 10th day of culturing in vitro, dark cell bodies - photoreceptors, light ones - cells of inner nuclear layer, punctuate line shows ganglion cell layer limits, scale bar represents $100 \mu \mathrm{m}$.

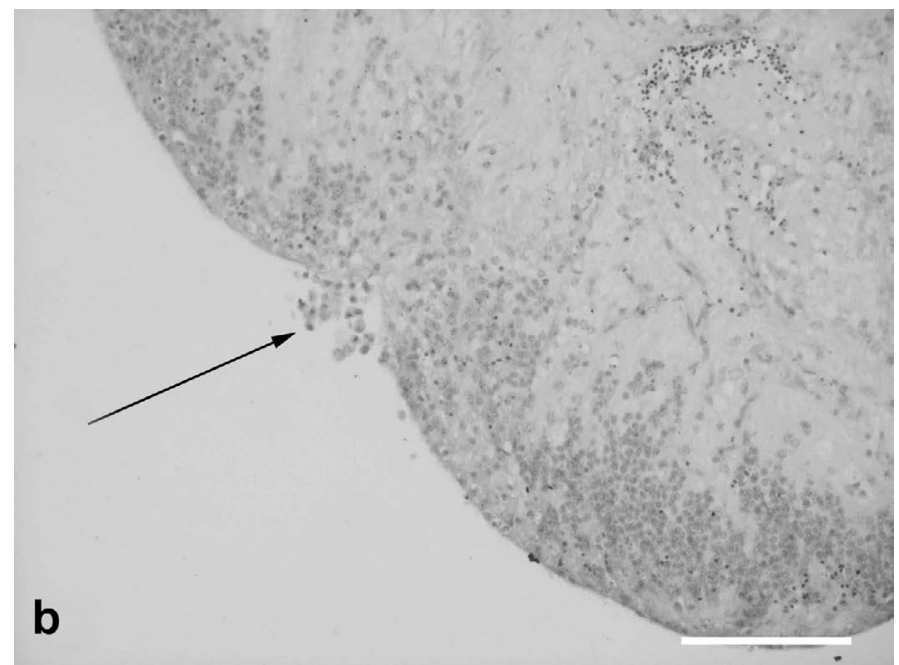

Figure 4b. Cell behavior in rat retina under conditions of long term organotypic roller culturing - fragment of the rat retina spheroid, arrow shows the zone of its closure, dark cell bodies - photoreceptors, light ones - cells of inner nuclear layer, scale bar represents $100 \mu \mathrm{m}$.

the photoreceptor cell segments were partly preserved; no signs of cell proliferation were detected, and the ganglion cell layer was actively infiltrated by macrophages, but the retina retained its stratification. In completely closed spheroids, structural rearrangements and cell responses were initiated that, taken together, provided evidence for retinal remodeling. Analysis of serial sections through such spheroids showed that part of photoreceptors in the ONL lost their processes and died, others migrated to the spheroid cavity, so that INL cells came to the outer surface of the spheroid (Figure 4a). It is noteworthy that the cells of the ganglion layer retained their location.

In the zone of spheroid closure (corresponding to the retinal periphery), neither migration of ora serrata cells to the spheroid cavity nor cell proliferation took place, unlike in the cultures of newt retina (Figure $4 \mathrm{~b}$ ). The cells of spheroids cultures for 10 days remained viable, and some non-neuronal cells showed mitotic activity. One to three mitoses were detected in each of serial sections through such spheroids. Morphological analysis of M-phase cells and their localization showed that there were at least two mitotically active cell populations: macrophage-like cells and sparse cells located in the INL, both in its outer part (closest to the surface after the inward migration of ONL cells) and in the inner part (Figures $4 \mathrm{c}, 4 \mathrm{~d}$ ). These relatively small cells, compared to macrophages, were attributed to the Müller cell population, although it is known that small populations of microand astroglia are also capable of division.

Thus, along with data obtained in other models considered above, the results of experiments with organotypic cultures of the adult rat retina confirm the possibility of its structural remodeling during survival in vitro. This process involves outward translocation of INL cells, in parallel with apoptosis of photoreceptor cell bodies and their displacement toward the outer surface and inside the explant; responses from macro- and microglia; and limited proliferation of nonneural cells. On the other hand, the stratified structure of the retina

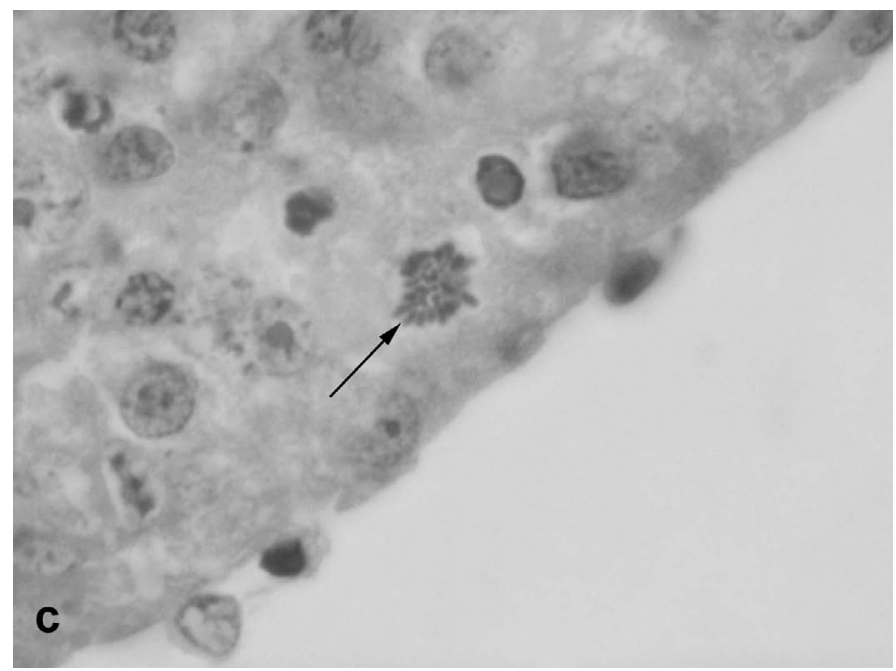

Figure 4c. Cell behavior in rat retina under conditions of long term organotypic roller culturing - mitosis (arrow) in the outer portion of rat retina in vitro, scale bar represents $10 \mu \mathrm{m}$.

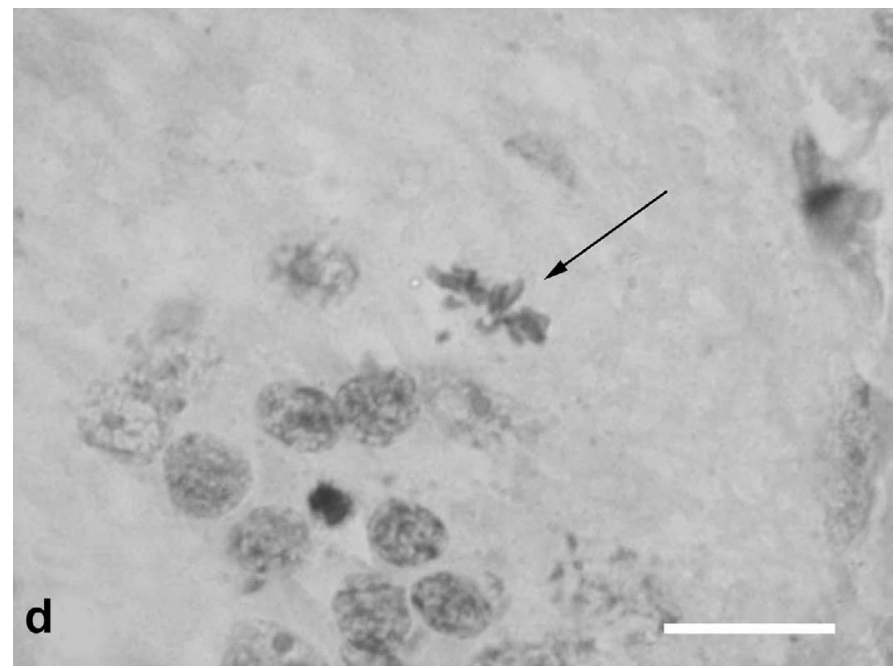

Figure 4d. Cell behavior in rat retina under conditions of long term organotypic roller culturing - mitosis (arrow) in the inner portion, among neural processes of cultured rat retina, scale bar represents $10 \mu \mathrm{m}$; Hematoxyline-Eosine. 
is largely retained, and the ganglion cell layer remains unchanged. This is evidence for the universality of responses contributing to the remodeling of this tissue after damage caused in different ways and in different animals. However, it should be emphasized once again that there is a major difference between the pattern of retinal remodeling in the newt, where a reserve of poorly differentiated (precursor) cells is actively involved in this process, and that in the rat, where no such reserve is available.

\section{Discussion}

Light-induced retinal degeneration (LIRD) is a convenient model for the study of retinal remodeling and reprogramming after photoreceptors' death [21]. Here, experiments with this model have been performed in newts and rats. The results obtained in newts show that 40-day exposure to bright leads to morphological changes in the retina that are indicative of its active remodeling. They include reduction and derangement of the photoreceptor outer segments, with some photoreceptor cell bodies dying off; activation, displacement, and differentiation of bipolar-like cells; the response from RPE cells, which detach from the epithelial layer, migrate, and acquire the properties of precursor cells and phagocytes; and hypertrophy of Müller cells, whose population increases. The main feature of retinal remodeling in newts is that at least three populations of precursor cells (growth zone cells, RPE cells, and bipolar-like cells with Landolt's club) are involved in the replacement of light-damaged neurons. Therefore, retinal remodeling in these animals can be described in terms generally used in developmental biology, such as cell migration, proliferation, de- and transdifferentiation. All these processes take place in the newt retina exposed to bright light in vivo and are even more clearly manifested in its organotypic culture in vitro. Precursor cells are actively incorporated into the retina, but not without errors, since they occur in ectopic sites. Retinal remodeling in this way allows restoration of tissue structure but apparently cannot ensure its normal functioning. Such a phenomenon, which has also been observed in the course of regenerative neurogenesis in the fish retina [24], appears to be characteristic of lower vertebrates with high regenerative potential.

In our opinion, the unique restorative capacity observed in the course of retinal remodeling in newts, but not in higher vertebrates, deserves greater attention from researchers as a striking example of successful utilization of endogenous reserves for regeneration of the retina. Recent data show that this phenomenon in newts is accounted for by two basic factors: the availability of competent cell sources and molecular regulatory mechanisms permitting cell type conversion $[25,11]$.

In rats, damage to the photoreceptor cell layer under the conditions used in this study does not lead to activation of potential precursor cells, which excludes the possibility of cell substitution. We have obtained no evidence for regeneration of the rat retina on account of any endogenous cell sources. In particular, experiments with the LIRD model have revealed no signs of formation of new photoreceptors from known potential sources such as Müller cells and precursor cells derived from the ciliary pigmented epithelium. This is not surprising: although these cell populations show a potential for conversion into photoreceptors under certain conditions (mostly in vitro), this potential is very limited [17].

Nevertheless, damage to the rat retina is followed by its structural remodeling with the involvement of certain cell populations, primarily those from the INL. As observed in our experiments, photoreceptor damage either in vivo or in vitro evokes response from macroglial
Müller cells. These cells, whose bodies are located in the INL and accessory prolongations extend from the vitreal surface of this layer to the RPE, contribute to the maintenance of biochemical and structural integrity of the retina [26]. In light-irradiated animals, the density of glial cell prolongations proved to be increased in areas of the inner plexiform layer associated with sites of ONL damage. This finding agrees with data on a surge of proliferative activity of glial cells and increase in their density in INL areas corresponding or adjacent to zones of damage in the outer portion of the retina $[27,28]$. The reactivity of macroglia is a well-known phenomenon that takes place in response to different kinds of retinal damage and is particularly important for glial scar formation, which may have future downstream effects on visual recovery [13]. We have observed distinct reactive gliosis in the rat retina under conditions of LIRD, which is additional evidence for the universality of this response in the retina of higher vertebrates. It is noteworthy that in the newt retina, which is known for its unique restorative capacity, Müller cells also respond to damage by proliferation and formation of increasingly dense and thick accessory prolongations. This has been observed in the experiments described above as well as under conditions of retinal detachment and other retinal injuries [29].

In addition to the impact on glia, bright light exposure also leads to changes in RPE regions corresponding to sites of ONL damage and photoreceptor cell death. Degeneration of photoreceptor outer segments is accompanied by the accumulation of phagosomes in RPE cells; moreover, these cells may also be directly damaged by highintensity light irradiation [30]. As follows from our data, RPE cells show reactivity in the course of retinal remodeling in both species used in this study. In rats, they detach from the epithelial layer, migrate, acquire a macrophage-like phenotype, and phagocytize damaged photoreceptor cells or their degenerating outer segments. The role of RPE cells in newts is more significant: in addition to the above functions, they provide precursors for replenishing populations of photoreceptor cells and neurons in the inner part of the retina (in the latter case, with the involvement of precursor cell proliferation).

In adult mammals, RPE cells divide rarely. There are data that these cells in mice can proliferate to some extent and, hence, have a limited ability to restore the RPE layer [31]. The same authors have also found that sites of local damage to the retina are naturally marked by RPE cell debris filled with melanin granules. It cannot be excluded, however, that these pigmented structures are aggregates of melanin granules released by the descendants of RPE cells migrating deep into the retina, up to the inner limiting membrane, as observed in our experiments with LIDR in newts. It is RPE cell migration toward the inner limiting membrane and their conversion into neuroblasts forming the retinal rudiment that account for regeneration of this tissue in the Anura [32]. This is additional evidence that the processes of retinal remodeling in different vertebrates are closely similar.

Attention should also be paid to changes in retinal bipolar cells in the course of degeneration of photoreceptor outer segments and cell bodies. In newts, there is a special late-developing population of displaced bipolars with Landolt's club (see above) that not only migrate outward from the INL but also serve as precursor cells for replacement of damaged photoreceptors (cones) [12]. In higher vertebrates, reprogramming of bipolar neurons has been described as a universal phenomenon in degenerative diseases of the retina [33], but the observed changes in these cells are generally limited to the loss of neurites and glutamate-dependent responses [34]. The answer to the question concerning the ability of these cells to perform any functions 
resembling those of photoreceptors appears to be negative, since there is no adequate cellular and molecular machinery. However, it should be noted that some relevant components have been detected in these cells, e.g., the recoverin protein in bipolar neurons from the human retina [35].

The overall anatomy of the retina in its inner part (the INL, inner plexiform layer, and ganglion cell layer) remains unchanged during the early stages of light damage. At subsequent stages, the formation of bucklings, outflow channels, and microneuromas is observed. Thus, retinal remodeling in all our models proved to be characterized by cell migration and translocation. In experiments with LIRD, such processes were observed for bipolar-like and RPE cells in the newt retina and in INL and RPE cells in the rat retina. Translocation of cell bodies and their clusters was even more distinct in retinal cultures. In closed spheroids formed by rat retinal explants, photoreceptor cell bodies moved from the ONL to the spheroid cavity, which was often accompanied by degeneration of the outer and inner segments and eventually of the photoreceptor as a whole. As a result of cell translocation and death in the ONL, the outer part of the spheroid was occupied by INL cells. Likewise, degeneration of photoreceptors with swollen and truncated outer segments has been observed in organotypic cultures of human neural retina [36].

Translocation of neurons is another universal mechanism of structural retinal remodeling in both higher and lower vertebrates, which has been described for bipolar, amacrine, and horizontal cells [37]. Cell displacement and translocation aimed at restoring the basic topology of the retina still continue at late stages of its remodeling. They may involve radial migration of neurons in two opposite directions, with bipolar and amacrine cells of the INL migrating to the ganglion cell layer and ganglion cells migrating to the INL [37]. In the course of normal development of the retina, cell translocation is one of mechanisms providing for cell specialization [38]. It may well be that processes of cell translocation and migration during retinal remodeling serve the same purpose but under conditions of pathologically altered cellular environment. There is increasing evidence for plasticity of the retina, which is the more surprising as the structure of this neural tissue in the norm is strictly maintained with respect to the numbers and composition of cells and the pattern of their interactions.

Thus, the results of our studies confirm the possibility of structural remodeling of the retina under conditions of LIRD in vivo and organotypic culture in vitro. In both cases, this process involves outward translocation of INL cells against the background of apoptosis and outward or inward displacement of photoreceptor cell bodies and responses from glial cells, while the stratified structure of the retina is largely retained. These events are similar to those described by other authors [21,1].

Another feature observed in both our models is that the ganglion cell layer remains unchanged with respect to both structural organization and cellularity. It has already been noted that, unlike second-order neurons (i.e., bipolar and horizontal cells), the ganglion cell population is relatively stable [39]. This fact is important, since it is the ganglion cell axons that form the optic nerve connecting the retina to the brain, and therefore preservation of the ganglion layer upon damage to the outer retina (photoreceptor layer) and during its remodeling provides the possibility of subsequent visual recovery. The loss of pre and/or postsynaptic inputs to the retinal neurons causes changes in their morphology and function, and, as a consequence, these neurons attempt to establish new synaptic contacts. Thus, the aforementioned changes in the retina can modify the transmission of information between its cells and thereby have an effect on the information that goes to the brain.

Retinal remodeling in lower vertebrates is a slow process that starts when part of the photoreceptor cell population dies off and initiates a regenerative response from precursor cells and associated structural rearrangements in the tissue. Even though cell substitution sometimes occurs with errors, in ectopic sites, and the restored connections are not always correct, this process is very important, because it serves to restore the cellularity and integrity of the retina. Therefore, analysis of mechanisms and pathways of precursor cell incorporation into retinal layers, the establishment of new connections between neurons, and molecular factors governing these events is a high priority for researchers. Studies in this field are highly relevant to the development of technologies for substituting dead retinal neurons by underdifferentiated precursor cells, stem cells, or induced pluripotent cells (from endo- or exogenous sources), with their subsequent differentiation in the preserved and functioning cellular environment of the retina. This approach appears to have a high therapeutic potential, since it may well provide for repair of retinal damage and visual recovery.

\section{Acknowledgments}

The authors would like to thank Kilina O.V. and prof. Philippov P.P. from MSU (Moscow) for technical support and discussion of the results on LIRD experiment with rats. This work was partially supported by Russian Foundation for Basic Research (RFBR) grant (\# 14-04-00184).

\section{References}

1. Marc RE (2010) Injury and repair: retinal remodeling. Encyclopedia of the Eye 414420.

2. Jones BW, Kondo M, Terasaki H, Lin Y, McCall M, et al.(2012) Retinal remodeling Jpn J Ophthalmol 56: 289-306. [Crossref]

3. Nagar S, Krishnamoorthy V, Cherukuri P, Jain V, Dhingra NK (2009) Early remodeling in an inducible animal model of retinal degeneration. Neuroscience 160: 517-529. [Crossref]

4. Stroeva OG, Mitashov VI (1983) Retinal pigment epithelium: proliferation and differentiation during development and regeneration.Int Rev Cytol83: 221-293. [Crossref]

5. Mitashov VI (1996) Mechanisms of retina regeneration in urodeles.Int J Dev Biol 40: 833-844. [Crossref]

6. Mitashov VI (1997) Retinal regeneration in amphibians.Int J Dev Biol 41: 893-905. [Crossref]

7. Grigoryan EN, Ivanova IP, Poplinskaya VA (1996) Discovery of new, internal sources of neural retina regeneration after its detachment in newts: I. A morphological and quantitative study. Izv Akad Nauk Ser Biol 319-332. [Crossref]

8. Grigorian EN, Mitashov VI (1985) Cultivation of the retinal pigment epithelium in the cavity of the lentectomized eye of newts.Ontogenez 16: 34-43. [Crossref]

9. Chiba C, Mitashov VI (2007) Cellular and molecular events in the adult newt retinal regeneration. In: Chiba Ch. (Ed.), Strategies for retinal tissue repair and regeneration in vertebrates: From fish to human, Research Signpost, Kerala, India, pp. 15-33.

10. Chiba $C$ (2014) The retinal pigment epithelium: an important player of retinal disorders and regeneration.Exp Eye Res 123: 107-114. [Crossref]

11. Grigoryan EN (2015) Competence factors of retinal pigment epithelium cells for reprogramming in the neuronal direction during retinal regeneration in newts. Izv Akad Nauk Ser Biol 5-16. [Crossref]

12. Grigoryan EN (2007) Alternative intrinsic cell sources for neural retina regeneration in adult urodelean amphibians. In: Chiba Ch. (Ed.), Strategies for retinal tissue repair and regeneration in vertebrates: From fish to human, Research Signpost, Kerala, India, pp. 35-62. 
13. Fisher SK, Lewis GP (2010) Injury and Repair Responses: Retinal Detachment. Encyclopedia of the Eye 428-438.

14. Ahmad I, Tang L, Pham H (2000) Identification of neural progenitors in the adult mammalian eye. Biochem Biophys Res Commun 270: 517-521. [Crossref]

15. Tropepe V, Coles BL, Chiasson BJ, Horsford DJ, Elia AJ, et al.(2000) Retinal stem cells in the adult mammalian eye.Science 287: 2032-2036. [Crossref]

16. Cicero SA, Johnson D, Reyntjens S, Frase S, Connell S, et al.(2009) Cells previously identified as retinal stem cells are pigmented ciliary epithelial cells.ProcNatlAcadSci USA 106: 6685-6690. [Crossref]

17. Yu H, Vu TH, Cho KS, Guo C, Chen DF (2014) Mobilizing endogenous stem cells for retinal repair.Transl Res 163: 387-398. [Crossref]

18. Fisher SK, Lewis GP (2003) Müller cell and neuronal remodeling in retinal detachment and reattachment and their potential consequences for visual recovery: a review and reconsideration of recent data.Vision Res 43: 887-897. [Crossref]

19. Grigorian EN, Poplinskaia VA (2002) Changes in the relative number of bipolarlike cells in the retina of Pleurodeleswaltl as a function of age and as a result of light exposure.Ontogenez 33: 111-117. [Crossref]

20. Abler AS, Chang CJ, Ful J, Tso MO, Lam TT (1996) Photic injury triggers apoptosis of photoreceptor cells.Res CommunMolPatholPharmacol92: 177-189. [Crossref]

21. Marc RE, Jones BW, Watt CB, Vazquez-Chona F, Vaughan DK, et al.(2008) Extreme retinal remodeling triggered by light damage: implications for age related macular degeneration. Mol Vis 14: 782-805. [Crossref]

22. Tanito M, Kaidzu S, Ohira A, Anderson RE (2008) Topography of retinal damage in light-exposed albino rats.Exp Eye Res 87: 292-295. [Crossref]

23. NovikovaIu P, Aleinikova KS, Krasnov MS, Poplinskaia VA, Grigorian EN (2010) In vitro organotypic cultivation of adult newt and rat retinas. IzvAkad Nauk Ser Biol 389402. [Crossref]

24. Stenkamp DL (2007) Neurogenesis in the fish retina.Int Rev Cytol259: 173-224. [Crossref]

25. Islam Md R, Nakamura K, Casco-Robles MM, Kunahong A, Inami W, et al.(2014) The newt reprograms mature RPE cells into a unique multipotent state for retinal regeneration. Scientific Reports4: e6043.

26. Bringmann A, Pannicke T, Grosche J, Francke M, Wiedemann P, et al. (2006) Müller cells in the healthy and diseased retina. Prog Retin Eye Res 25: 397-424. [Crossref]
27. Fisher SK, Erickson PA, Lewis GP, Anderson DH (1991) Intraretinal proliferation induced by retinal detachment.Invest Ophthalmol Vis Sci 32: 1739-1748. [Crossref]

28. Lewis GP, Guérin CJ, Anderson DH, Matsumoto B, Fisher SK (1994) Rapid changes in the expression of glial cell proteins caused by experimental retinal detachment.Am J Ophthalmol 118: 368-376. [Crossref]

29. Grigoryan EN, Anton HJ, Poplinskaya VA, Aleinikova KS, Domaratskaya EI,et al. (2012) Signs of Müller cell gliotic response found in the retina of newts exposed to real and simulated microgravity. Adv Space Res 49: 1465-1471.

30. Wu J, Seregard S, Algvere PV (2006) Photochemical damage of the retina SurvOphthalmol 51: 461-481. [Crossref]

31. Machalinska A, Kawa MP, Pius-Sadowska E, Roginska D, Klos P, et al. (2013) Endogenous regeneration of damaged retinal pigment epithelium following low dose sodium iodate administration: an insight into the role of glial cells in retinal repair. Exp Eye Res 112: 68-78. [Crossref]

32. Yoshii Ch, Ueda Y, Okamoto M, Araki M (2007) Neural retinal regeneration in the anuran amphibian Xenopuslaevis post-metamorphosis: transdifferentiation of retinal pigmented epithelium regenerates the neural retina. DevBiol 303: 45-56. [Crossref]

33. Marc RE, Jones BW, Anderson JR, Kinard K, Marshak DW, et al.(2007) Neura reprogramming in retinal degeneration.Invest Ophthalmol Vis Sci 48: 3364-3371. [Crossref]

34. Varela C, Igartua I, De la Rosa EJ, De la Villa P (2003) Functional modifications in rod bipolar cells in a mouse model of retinitis pigmentosa. Vision Res 43: 879-885. [Crossref]

35. Wiechmann AF, Hammarback JA (1993) Expression of recoverin mRNA in the human retina: localization by in situ hybridization. Exp Eye Res 57: 763-769. [Crossref]

36. Fernandez-Bueno I, Fernández-Sánchez L, Gayoso MJ, García-Gutierrez MT, Pastor JC, et al. (2012) Time course modifications in organotypic culture of human neuroretina. Exp Eye Res 104: 26-38. [Crossref]

37. Cuenca N, Fernandez-Sanchez L, Campello L, Maneu V,De la Villa P, et al. (2014) Cellular responses following retinal injuries and therapeutic approaches for neurodegenerative diseases. Prog Ret Eye Res 43: 17-75. [Crossref]

38. Baye LM, Link BA (2008) Nuclear migration during retinal development.Brain Res 1192: 29-36. [Crossref]

39. Mazzoni, F, Novelli, E, Strettoi, E., 2008. Retinal ganglion cells survive and maintain normal dendritic morphology in a mouse model of inherited photoreceptor degeneration. J Neurosci 28: 14282-14292. [Crossref]

Copyright: $\odot 2016$ Grigoryan EN. This is an open-access article distributed under the terms of the Creative Commons Attribution License, which permits unrestricted use, distribution, and reproduction in any medium, provided the original author and source are credited. 